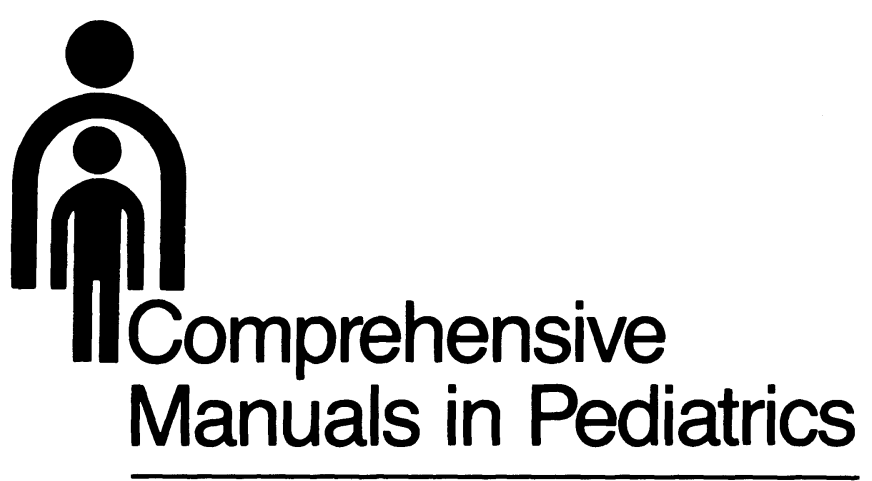

Series Editors

Michael Katz

E. Richard Stiehm 


\section{Pediatric \\ Infectious Diseases for the Practitioner}

Melvin I. Marks, M.D.

With 83 Illustrations, 12 in Full Color

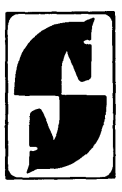

Springer-Verlag

New York Berlin Heidelberg Tokyo 
Melvin I. Marks, M.D., University of Oklahoma College of Medicine, Department of Pediatrics, Oklahoma Children's Memorial Hospital, 940 Northeast 13th Street, Oklahoma City, Oklahoma 73190, U.S.A.

\section{SERIES EDITORS}

Michael Katz, M.D. Reuben S. Carpentier Professor and Chairman, Department of Pediatrics, College of Physicians and Surgeons, Columbia University; and Director, Pediatric Service, Presbyterian Hospital (Babies Hospital), New York, New York, U.S.A.

E. Richard Stiehm, M.D., Professor of Pediatrics, UCLA School of Medicine, UCLA Hospitals and Clinics, Los Angeles, California, U.S.A.

Library of Congress Cataloging in Publication Data

Marks, M. I. (Melvin I.)

Pediatric infectious diseases for the practitioner.

(Comprehensive manuals in pediatrics)

Includes bibliographical references and index.

1. Communicable diseases in children-Handbooks,

manuals, etc. I. Title. II. Series. [DNLM:

1. Communicable Diseases-in infancy \& childhood.

WC $100 \mathrm{M} 346 \mathrm{p}]$

RJ401.M37. 1984. 618.92’9. 84-13837

(c) 1985 by Springer-Verlag New York, Inc.

Softcover reprint of the hardcover 1st edition 1985

All rights reserved. No part of this book may be translated or reproduced in any form without written permission from Springer-Verlag, 175 Fifth Avenue, New York, New York 10010 , U.S.A. The use of general descriptive names, trade names, trademarks, etc., in this publication, even if the former are not especially identified, is not to be taken as a sign that such names, as understood by the Trade Marks and Merchandise Marks Act, may accordingly be used freely by anyone.

While the advice and information of this book is believed to be true and accurate at the date of going to press, neither the authors nor the editors nor the publisher can accept any legal responsibility for any errors or omissions that may be made. The publisher makes no warranty, express or implied, with respect to material contained herein.

Typeset by International Computaprint Corporation, Horsham, Pennsylvania. 
To those who care for children 


\section{Contents}

\section{Series Foreword}

Michael Katz and E. Richard Stiehm

xxvii

\section{Preface}

Acknowledgement

xxix

Color Insert

$\mathrm{xxxi}$

xxxiii

1 Pediatric Immunizations

General 1

International Travel 1

Pregnancy 1

Hypersensitivity 2

Malignancies/Immunosuppression 2

Seizures 2

Conventional Vaccines 3

B.C.G. 3

Diphtheria, Tetanus, Pertussis (DTP) 4

DT-Adult 5

Hepatitis 5

Influenza 11

Measles 12

Meningococcus: Groups A and C 13

Mumps 14

Pertussis 14

Pneumococcus 14

Poliovirus 15

Rabies 16

Rubella 16

Smallpox $\quad 17$

Tetanus 20 
viii Contents

Combined Vaccines 21

Mixed Bacterial Vaccines and "Cold Shots" 21

Experimental Immunizations 22

References 23

\section{Antimicrobial Therapy}

Principles 32

Drug Choice 33

Dose/Frequency 34

Route 34

Therapeutic Monitors 36

Duration of Therapy $\quad 38$

Host Factors $\quad 38$

Mechanisms of Action 39

Combinations $\quad 39$

Antimicrobial Prophylaxis 40

Resistance 42

Toxicity 42

Specific Recommendations $\quad 45$

I. Antibacterials 45

II. Antifungals 79

III. Antiparasitics 83

IV. Antiprotozoals 88

V. Antivirals 90

VI. Miscellaneous 92

VII. Summary of Antimicrobial Choices 93

References $\quad 98$

3 Infections of the Newborn

General Considerations 123

Newborn Environments 123

Immunity 126

Clinical Manifestations $\quad 127$

Congenital and Perinatal Infections

Cytomegalovirus $\quad 127$

Congenital Rubella 131

Congenital and Perinatal Herpes Simplex Infections

Congenital Toxoplasmosis 139

Hepatitis 141

Congenital and Neonatal Varicella 143

Mumps 145

Measles 145

Lymphocytic Choriomeningitis Virus $\quad 146$ 
Acquired Neonatal Infections: Specific Causes 146

Group B Streptococcus 146

Other Streptococci 149

E. coli and Gram-Negative Enteric Infections 149

Staphylococcus 152

Salmonella $\quad 155$

Listeria $\quad 156$

Syphilis $\quad 157$

Gonococcal Infection $\quad 159$

Tuberculosis 162

Anaerobes 166

Fungal Infections 166

Enterovirus $\quad 168$

Chlamydia 169

Acquired Neonatal Infections: Clinical Syndromes 171

Neonatal Sepsis 171

Meningitis 177

Respiratory Infections 179

Urinary Tract Infection $\quad 184$

Osteomyelitis/Arthritis $\quad 185$

Diarrhea 186

C. difficile and Antibiotic-Associated Diarrhea 188

Necrotizing Enterocolitis 188

Skin Infections 190

Eye Infections 191

Otitis Media 191

References 192

\section{Upper Respiratory Infections}

Epidemiology 216

Etiology 217

Treatment and Prevention 217

Frequent Respiratory Infections 217

Rhinitis 218

Etiology 218

The Common Cold Syndrome 220

Allergic Rhinitis 220

Pharyngitis/Tonsillitis 222

Etiology 222

Streptococcal Pharyngitis 222

Diagnosis 224

Non-Group A Streptococcus Bacterial Infection 226

Diphtheria 226

Epidemiology/Pathogenesis 226

Nonbacterial Causes of Pharyngitis 228 
Otitis 229

Otitis Externa: Acute 230

Otitis Externa: Chronic 230

Otitis Externa: Invasive 231

Otitis Media 231

Chronic Suppurative Otitis Media 239

Serous Otitis Media 240

Mastoiditis 241

Pathogenesis/Etiology 241

Sinusitis 241

Pathogenesis 242

Infections in and Around the Eye 246

Periorbital Cellulitis 248

Conjunctivitis 251

Epidemiology/Etiology 251

Adenovirus Conjunctivitis 253

The Conjunctivitis-Otitis Syndrome 253

Chlamydia Conjunctivitis $\quad 256$

Clinical Manifestations 256

Diagnosis 257

Treatment 257

Prevention 258

Prognosis 258

Herpes Simplex Eye Infections 258

Clinical Features 258

Diagnosis 259

Management 259

Other Causes of Keratitis $\quad 260$

Endophthalmitis 260

Pathogenesis/Etiology 260

Clinical Manifestations/Diagnosis

Treatment 261

Chorioretinitis 262

Soft Tissue Infections: Head and Neck 263

Pathogenesis and Etiology 263

Clinical Manifestations 263

Diagnosis 264

Differential Diagnosis 264

Treatment 264

Complications 265

Epiglottitis 265

Etiology and Pathogenesis 265

Clinical Manifestations 266

Diagnosis 266

Treatment 267

Prognosis 267 


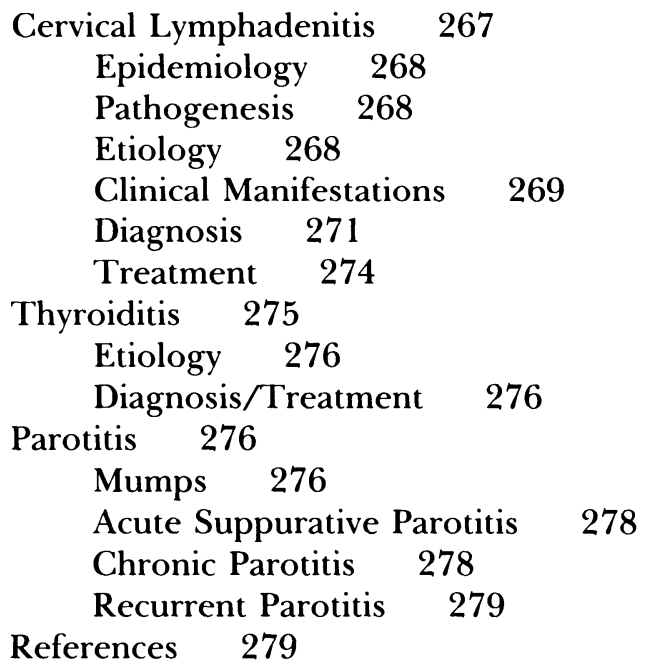

\section{Lower Respiratory Infections}

General Considerations 292

Pathogenesis/Etiology 292

Clinical Manifestations 293

Diagnosis 294

Therapy 294

Prevention 295

Croup 295

Epidemiology 296

Etiology 296

Clinical Manifestations $\quad 297$

Diagnosis 298

Treatment 298

Prognosis 300

Tracheitis 301

Pathogenesis/Etiology 301

Clinical Manifestations/Diagnosis 301

Treatment 301

Tracheobronchitis $\quad 302$

Community-Acquired 302

Hospital-Acquired 302

Bronchitis 303

Pathogenesis 304

Etiology 304

Treatment 305

Prevention 305

Bronchiolitis 306

Epidemiology 306 
xii Contents

Etiology 306

Clinical Manifestations $\quad 307$

Diagnosis 307

Therapy 308

Prognosis 308

Prevention 309

Pneumonia 309

Epidemiology 309

Pathogenesis $\quad 310$

Etiology $\quad 310$

Clinical Manifestations $\quad 313$

Diagnosis $\quad 313$

Differential Diagnosis 317

Treatment $\quad 318$

Prevention 319

Complications $\quad 320$

Empyema 321

Epidemiology 321

Pathogenesis 321

Etiology 322

Clinical Manifestations $\quad 323$

Diagnosis 323

Differential Diagnosis 325

Therapy 325

Prognosis 327

Lung Abscess $\quad 328$

Pathogenesis/Etiology 328

Clinical Presentation/Diagnosis 329

Treatment 329

Prognosis $\quad 330$

Chlamydia Pneumonia 330

Psittacosis $\quad 330$

Chlamydia trachomatis Pneumonia 331

Pertussis 332

Epidemiology 332

Pathogenesis 333

Etiology 333

Clinical Manifestations 333

Diagnosis 334

Therapy 335

Complications $\quad 336$

Prevention $\quad 337$

Mycoplasma 339

Epidemiology 339

Etiology 339 
Clinical Manifestations $\quad 339$

Diagnosis $\quad 340$

Treatment 341

Complications 341

Prognosis 342

Pulmonary Tuberculosis 342

Epidemiology $\quad 342$

Pathogenesis 343

Clinical/Radiographic Manifestations 344

Diagnosis 345

Therapy 347

Prevention 349

Mycobacteriosis $\quad 350$

Cystic Fibrosis 351

Clinical Manifestations 351

Diagnosis 352

Treatment 353

Isolation $\quad 356$

Pneumocystis carinii Pneumonia 356

Clinical Manifestations $\quad 356$

Diagnosis 356

Treatment 358

Prevention 358

Toxocariasis $\quad 359$

Epidemiology/Pathogenesis $\quad 359$

Etiology $\quad 359$

Clinical Manifestations $\quad 359$

Diagnosis $\quad 360$

Therapy 360

Prognosis 361

Prevention 361

Histoplasmosis $\quad 361$

Epidemiology 361

Clinical Manifestations 362

Diagnosis 362

Therapy 363

Extrapulmonary Histoplasmosis 364

Coccidioidomycosis 365

Acute Self-Limited Infection 365

Progressive Pneumonia and Disseminated Infection 365

Diagnosis $\quad 365$

Treatment 366

Legionellosis $\quad 366$

Epidemiology 366

Etiology $\quad 367$ 


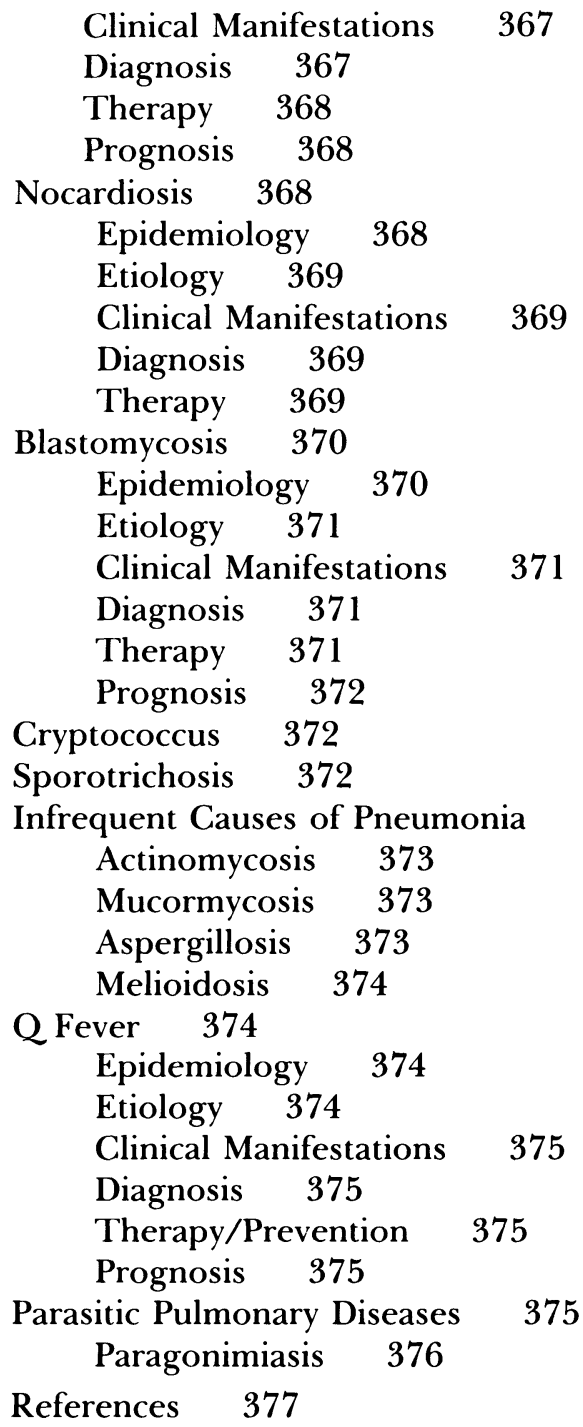

6 Gastrointestinal Infections

Gastroenteritis 396

Epidemiology 396

Pathogenesis 397

Etiology 399

Clinical Manifestations 403

Diagnosis 406

Treatment 409 


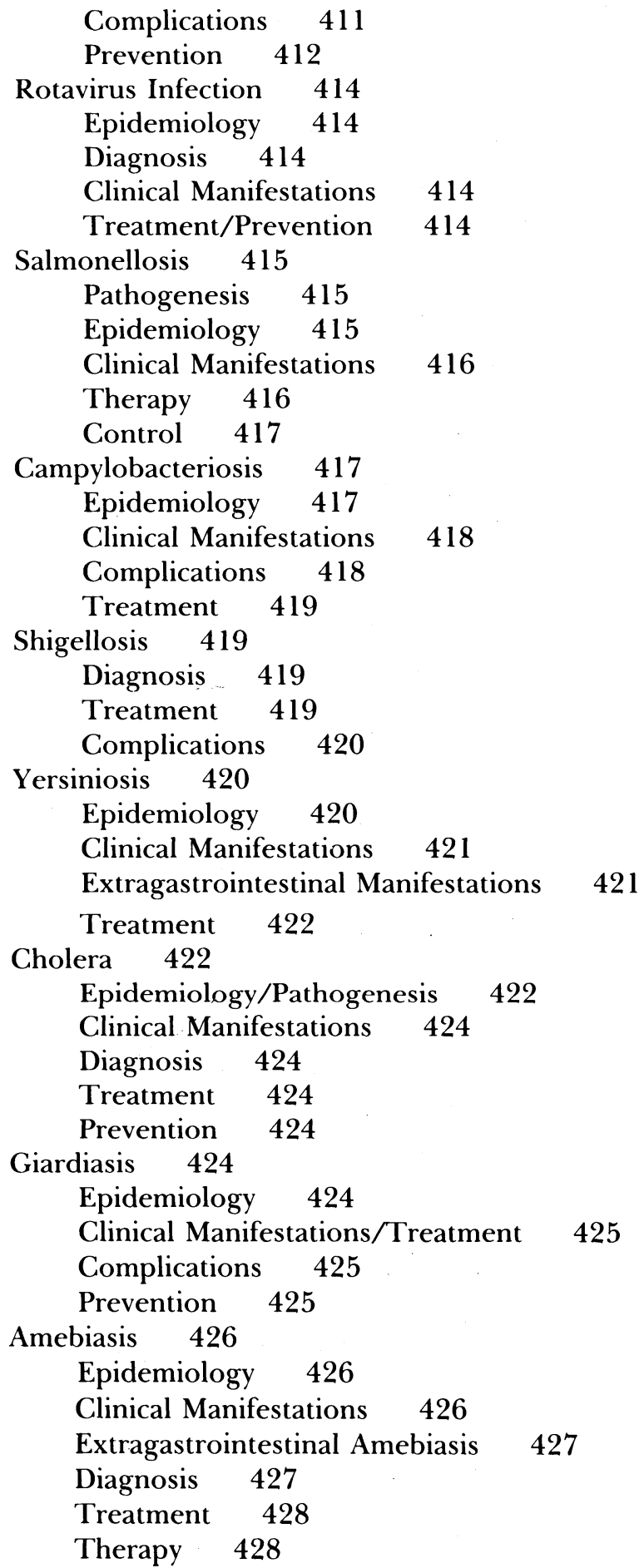


Stomatitis $\quad 428$

Acute Stomatitis $\quad 428$

Recurrent Stomatitis 430

Esophagitis 431

Pathogenesis 431

Etiology 432

Diagnosis 432

Treatment: Candida Esophagitis 432

Treatment: Herpes Esophagitis 433

Tuberculosis 433

Complications 433

Hepatitis 433

Epidemiology 433

Etiology 435

Clinical Manifestations $\quad 436$

Diagnosis 438

Prognosis/Complications $\quad 440$

Prevention 440

Parasitic Causes of Hepatitis 441

Hepatic, Splenic, and other Intraabdominal Abscesses 443

Pathogenesis/Etiology 443

Clinical Manifestations 443

Diagnosis 444

Treatment 444

Cholecystitis 444

Pathogenesis/Epidemiology 444

Etiology 444

Clinical Manifestations $\quad 445$

Diagnosis 445

Treatment 445

Cholangitis 446

Clinical Features/Pathogenesis/Etiology 446

Diagnosis 446

Treatment 446

Pancreatitis 447

Pathogenesis 447

Etiology 447

Clinical Manifestations 447

Diagnosis 447

Complications 448

Management 449

Peritonitis 449

Pathogenesis 449

Etiology 449

Clinical Manifestations 451 


$\begin{array}{lcc}\text { Diagnosis } & 451 & \\ \text { Treatment } & 452 & \\ \text { Prevention } & 453 & \\ \text { Complications } \quad 453 & \\ \text { Appendicitis } & 454 & \\ \text { Etiology } & 454 & \\ \text { Differential } & \text { Diagnosis } & 454 \\ \text { Clinical Manifestations } & 445 \\ \text { Complications } \quad 455 & \\ \text { Treatment/Prevention } & 455 \\ \text { References } 456 & \end{array}$

7 Skin Infections

Skin Infections 476

Nonspecific Rash and Systemic Infection $\quad 476$

Mycoplasma $\quad 477$

Rashes Involving the Palms and Soles 479

Specific Rashes $\quad 480$

Skin Infection Associated with Animal Contact 481

Tick Bites 481

Viral and Presumably Viral Syndromes 481

Measles 481

Varicella $\quad 487$

Herpes Zoster 492

Rubella 494

Hand, Foot, and Mouth Disease 494

Herpes Simplex Infections of the Skin 496

Warts 500

Molluscum Contagiosum 502

Roseola Infantum 503

Erythema Infectiosum 504

Mucocutaneous Lymph Node Syndrome (Kawasaki Disease) 505

Bacterial Skin Infections 509

Furunculosis/Abscess $\quad 509$

Cellulitis $\quad 512$

Impetigo 515

Staphylococcal Scalded Skin Syndrome $\quad 518$

Toxic Shock Syndrome 521

Scarlet Fever 524

Wound Infection 525

Leprosy $\quad 528$

Pinta 530

Yaws 531 
xviii Contents

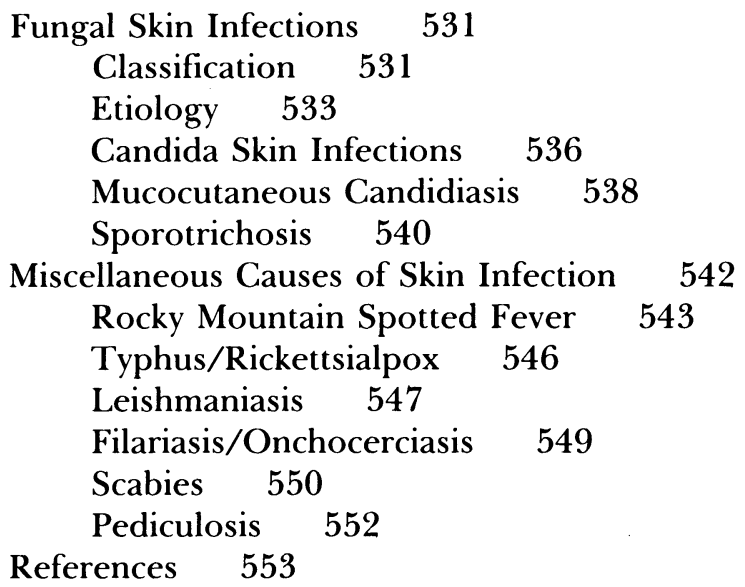

8 Bone and Joint Infections 569

\begin{tabular}{|c|c|c|}
\hline Osteomyelitis & 569 & \\
\hline Epidemiolog & 569 & \\
\hline Pathogenesis & 570 & \\
\hline Etiology & 570 & \\
\hline Diagnosis & 573 & \\
\hline Treatment & 575 & \\
\hline Prognosis & 579 & \\
\hline Arthritis $\quad 579$ & & \\
\hline Pathogenesis & 580 & \\
\hline Etiology & 581 & \\
\hline Clinical Man & nifestations & 582 \\
\hline Lyme Arthrit & itis $\quad 582$ & \\
\hline Diskitis $\quad 5$ & 583 & \\
\hline Sacroiliac Ar & rthritis & 584 \\
\hline Diagnosis of & f Arthritis & 584 \\
\hline Differential I & Diagnosis & 587 \\
\hline Treatment & 587 & \\
\hline Followup and Pro & ognosis & 590 \\
\hline References & & \\
\hline
\end{tabular}

9 Neurologic Infections 596

Meningitis 596

Pathogenesis 596

Etiology 597

Clinical Manifestations 599

Diagnosis 600 


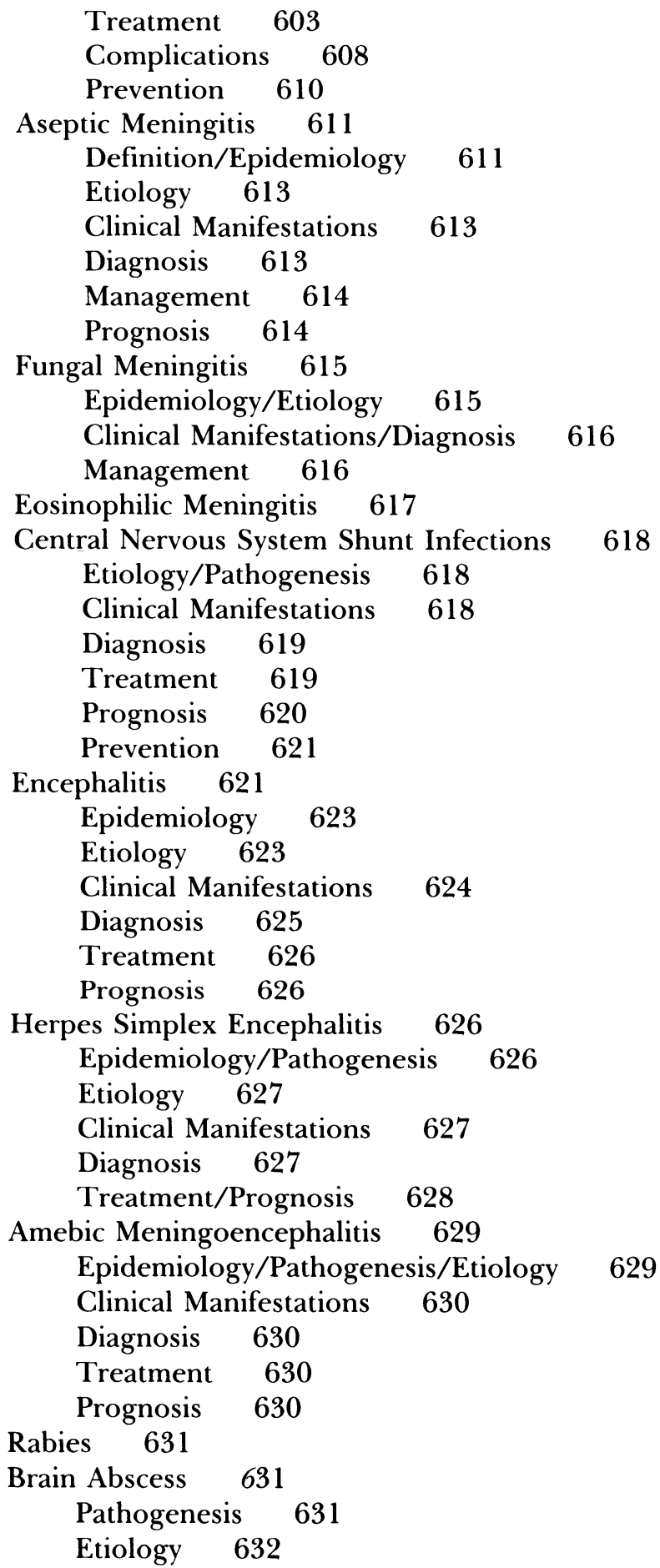


Clinical Manifestations

633

Diagnosis 633

Treatment 634

Prognosis 635

Subdural/Epidural Abscess 635

Clinical Manifestations/Diagnosis 635

Management 636

Tetanus 636

Epidemiology 636

Etiology 636

Clinical Manifestations

637

Diagnosis 637

Treatment 638

Botulism 638

Etiology/Pathogenesis $\quad 638$

Clinical Manifestations 638

Diagnosis 639

Therapy 639

Infant Botulism 639

Reye Syndrome $\quad 640$

References 640

10 Genitourinary Infections

Urinary Tract Infections 652

Epidemiology/Pathogenesis 652

Etiology 654

Clinical Manifestations $\quad 655$

Diagnosis 656

Treatment 659

Prognosis 662

Renal Abscess 663

Epidemiology/Pathogenesis $\quad 663$

Etiology 663

Clinical Manifestations $\quad 664$

Diagnosis $\quad 664$

Treatment 664

Urethritis 664

Epidemiology/Pathogenesis $\quad 664$

Etiology 665

Clinical Manifestations $\quad 666$

Diagnosis $\quad 666$

Treatment 666

Prostatitis 667

Vaginitis $\quad 667$

Clinical Manifestations $\quad 667$ 
Etiology $\quad 667$

Diagnosis 668

Treatment 669

Pelvic Inflammatory Disease $\quad 670$

Epidemiology/Pathogenesis $\quad 670$

Etiology $\quad 670$

Clinical Manifestations $\quad 670$

Diagnosis 671

Treatment 672

Complications $\quad 673$

Epididymitis/Orchitis 673

Etiology/Clinical Manifestations 673

Diagnosis 673

Therapy 673

Gonorrhea 674

Clinical Manifestations $\quad 674$

Diagnosis 675

Treatment 676

Complications 676

Genital Herpes 678

Epidemiology/Etiology $\quad 678$

Clinical Manifestations $\quad 678$

Diagnosis 678

Treatment $\quad 679$

Prognosis 679

Chlamydial Genitourinary Infections $\quad 680$

Clinical Features $\quad 680$

Diagnosis 680

Treatment 680

Complications 681

Lymphogranuloma Venereum 681

Etiology/Diagnosis 681

Syphilis $\quad 682$

Clinical Manifestations 682

Diagnosis 683

Treatment 683

Chancroid 684

Treatment 685

Sexually Transmitted Diseases in Abused Pediatric Patients 685

References 686

\section{Cardiovascular Infections}

Endocarditis 696

Pathogenesis 696

Etiology $\quad 697$ 
xxii Contents

Clinical Manifestations $\quad 699$

Diagnosis 700

Acute Complications 701

Treatment 702

Prevention 704

Prognosis 704

Fungal Endocarditis $\quad 705$

Myocarditis 706

Epidemiology 706

Pathogenesis 706

Etiology 707

Clinical Manifestations $\quad 707$

Diagnosis 708

Treatment 709

Complications 709

Prognosis 710

Pericarditis 710

Epidemiology/Pathogenesis $\quad 710$

Etiology 710

Clinical Manifestations 711

Diagnosis 712

Treatment 713

Prognosis 714

References $\quad 714$

12 Systemic Infections in Normal and Immunocompromised Hosts

Systemic Infections Presenting as Fever 719

Fever $\quad 719$

Acute Fever $\quad 720$

Persistent Fever/Fever of Unknown Origin (FUO) 722

Relapsing Fever 723

Fever and Myalgia 724

Typhoid and Enteric Fever $\quad 725$

Epidemiology/Pathogenesis 725

Clinical Manifestations $\quad 725$

Diagnosis 726

Treatment 726

Prevention 727

Bacteremia/Septicemia 727

Epidemiology/Etiology/Pathogenesis $\quad 727$

Clinical Manifestations $\quad 728$

Diagnosis 729

Treatment 731 
Septic Shock 731

Etiology/Pathogenesis 731

Diagnosis/Clinical Manifestations 732

Treatment 733

Prognosis 736

Infectious Mononucleosis and Other Epstein-Barr Virus Infections 736

Epidemiology/Etiology $\quad 736$

Clinical Manifestations 736

Diagnosis 738

Treatment 739

Prognosis 739

Leptospirosis $\quad 740$

Epidemiology/Etiology $\quad 740$

Clinical Manifestations 741

Diagnosis 741

Treatment 741

Brucellosis 742

Etiology/Pathogenesis $\quad 742$

Clinical Manifestations 742

Diagnosis 742

Treatment 743

Tularemia $\quad \mathbf{7 4 3}$

Epidemiology 743

Etiology 743

Clinical Manifestations $\quad 744$

Diagnosis 745

Treatment 745

Prevention 746

Plague 746

Epidemiology/Etiology $\quad 746$

Clinical Manifestations $\quad 746$

Diagnosis 747

Treatment 747

Trichinosis 747

Epidemiology/Pathogenesis $\quad 747$

Clinical Manifestations $\quad 748$

Diagnosis 748

Treatment 749

Malaria 749

Epidemiology 749

Clinical Manifestations $\quad 750$

Diagnosis 751

Treatment 751

Prevention 752

Trypanosomiasis $\quad 752$ 


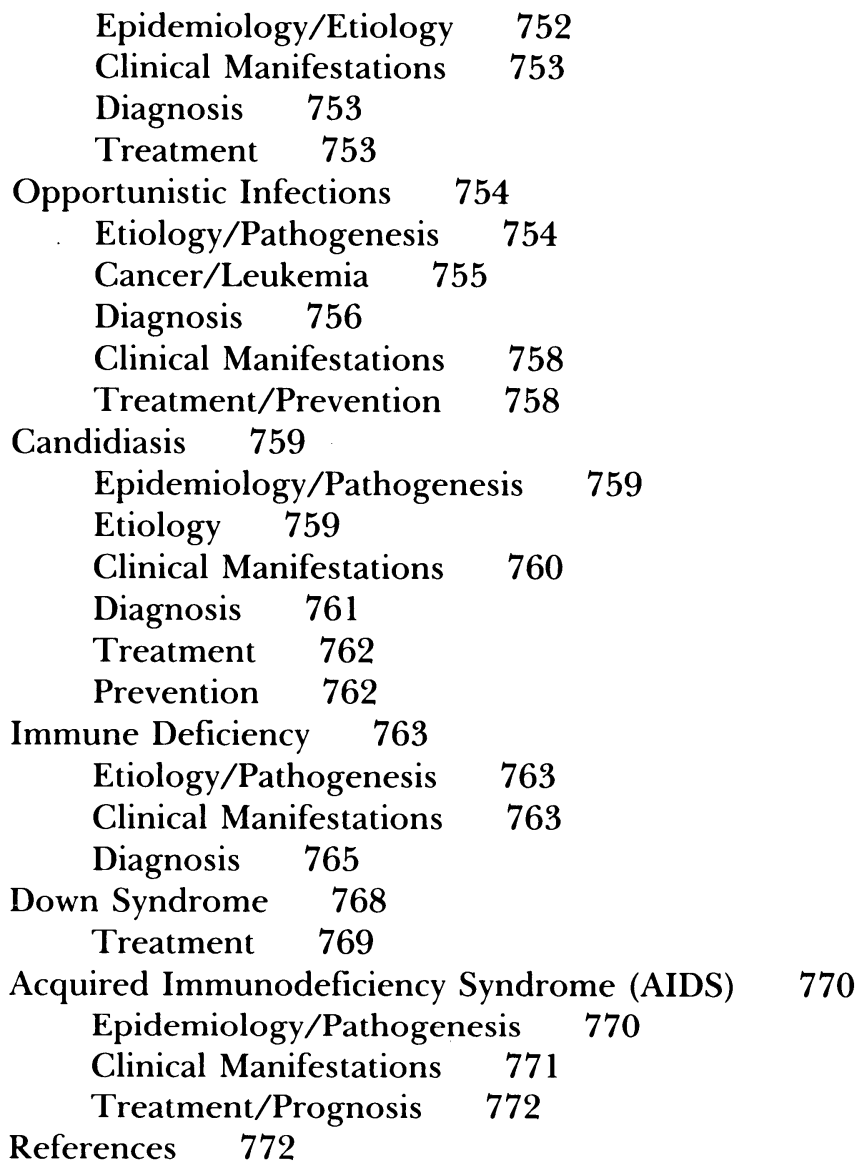

\section{Nosocomial Infections}

Definition 790

Surveillance/Epidemiology $\quad 790$

Control Measures 793

Special Units 797

Handwashing Facilities $\quad 797$

Visiting Policies 797

Specific Recommendations 797

Definitions 808

Major Isolation Categories $\quad 808$

Isolation and Precaution Techniques 808

Respiratory Isolation $\quad 808$

Strict Isolation 809

Protective Isolation 809

Enteric Isolation $\quad 809$ 
Wound and Skin Isolation 810

Secretion Precautions (Lesions and Oral) 810

Excretion Precautions 811

Blood Precautions 811

Personnel Guidelines $\quad 812$

Respiratory Infection 812

Herpes Infection 812

General Considerations for Newborns $\quad 812$

References 816

Index 


\section{Series Foreword}

Comprehensive Manuals in Pediatrics are designed to broaden the practitioner's clinical scope by providing a wide range of diagnostic and management skills ordinarily considered to be the exclusive domain of the specialists. Although the series as a whole constitutes a comprehensive text in pediatrics, each volume stands on its own as a self-contained reference for the busy practitioner.

In order to maintain a uniform style and coverage of each subject, each manual is usually written by no more than one or two authors. Each author is an acknowledged expert in his or her field and provides a comprehensive, up-to-date account of the topic under discussion. Practically oriented, each volume offers concise guidelines and courses of treatment.

Michael Katz

E. Richard Stiehm 


\section{Preface}

The preface-my opportunity to rationalize this labor, titillate the reader, philosophize or otherwise self-indulge. I'll take full advantage.

Why write a book? After fifteen years' experience as an infectious disease consultant, teacher and researcher, I feel it is time to speak out! I have spent the majority of my waking hours thinking, reading and writing about childrens' infectious disease problems, have amassed a veritable Fort Knox of publications on the subject and have been reasonably outspoken. Yet the field continues to progress with reckless speed and the gaps between our knowledge and effective communication of new information remain wide. I am eager to accept more responsibility for teaching yet my audience has been limited. This, added to my frustration with multi-authored texts, prompted me to write this book.

Who is the book intended for? This book is intended for and dedicated to those who will take the time to read it - my comrades in arms! Facetious as it may seem, readers are not as frequent as purchasers and purchasers not as frequent as health care providers. I hope the contents will appeal to students, primary care clinicians and their assistants, and trainees and practitioners in infectious diseases and clinical microbiology. They see a patient, have the courage to make a diagnosis, to change it if appropriate events arise, to withhold antibiotics, to admit their lack of knowledge, to seek help in these pages and from their colleagues, and to dedicate themselves to continue to learn from their patients and each other.

What is the book about? This book concerns common pediatric infectious disease problems. The system approach is used (e.g., respiratory, gastrointestinal, skin infections) and is considered in terms of viral, bacterial, and fungal causes of illness. Mycoplasma, protozoa, chlamydia, parasites and rickettsia are also included where appropriate, as are noninfectious causes. I give special consideration to immunizations, antimicrobial therapy and to particular groups, such as newborns. I refer to problems that I have seen repeatedly for purposes of teaching and illustration. Let's 
face it, many of the common infectious diseases of children are selflimiting and benign and can be diagnosed and handled in several fashions, often of equal validity. The most important lessons for the doctor are often provided by the most difficult and unusual cases. Thus I am not taking an ivory tower view of infectious diseases, but rather trying to use the type of case a consultant like myself might see to illustrate principles of diagnosis and management applicable to common problems in practice.

How will this book achieve the goals of teaching students and helping practitioners? I often judge a book by consulting it several times in reference to specific problems about my patients or questions raised by students. After several attempts to consult the index to guide me to the information I am seeking, I can usually begin to evaluate the practical usefulness of the text. Drawing upon that experience, I hope the index of this book proves to be replete with useful citations so that readers may easily be guided to informative, well organized content. Emphasis on clinical presentation, and liberal use of tables for listing causes, differential diagnoses, diagnostic aids and therapies should be especially helpful. Recent references are offered throughout the text for those interested in additional reading and to support more contentious statements.

Finally, no preface would be complete without a philosophical note. When I began to write this book, I felt like an explorer embarking on a new journey. It was with a mixture of excitement and apprehension that I set sail, hoping to effectively bridge the gap between the microbiological sciences and clinical infectious diseases. I hope this has been a successful journey.

Melvin I. Marks 


\section{Acknowledgement}

Writing a single-authored textbook is like having a child. This one was inspired by my teachers and role models, Henry Kempe, Keith Drummond, Mary Ellen Avery and Theodore Eickhoff. The opportunity was provided by Michael Katz, E. Richard Stiehm and Springer-Verlag. The long arduous gestation required much love and understanding from my wife Susan, and my children, Suzanne, Jennifer and Daniel. Birth was facilitated by expert care from Joyce Bagan, Rose Stursa and Harris Stutman. Finally, I acknowledge the readers who will share the reward, but also the responsibility for this book's future growth and development. 
Color Insert xxxiii
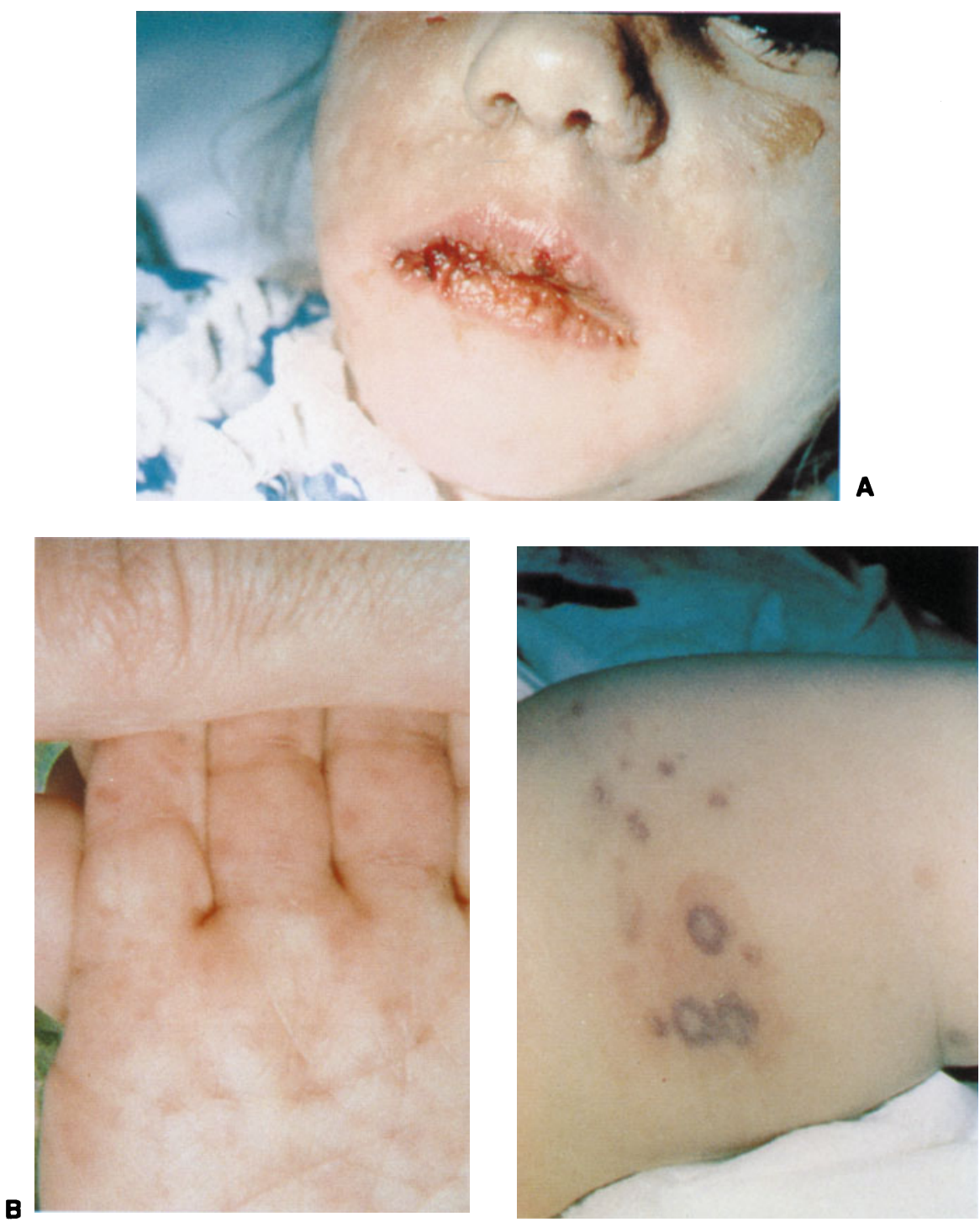

C

Figure 2-4. Three manifestations of antibiotic-associated erythema multiforme. A: Mucosal ulceration. B: Palmar rash. C: Hemorrhagic target lesions (see p. 44). 


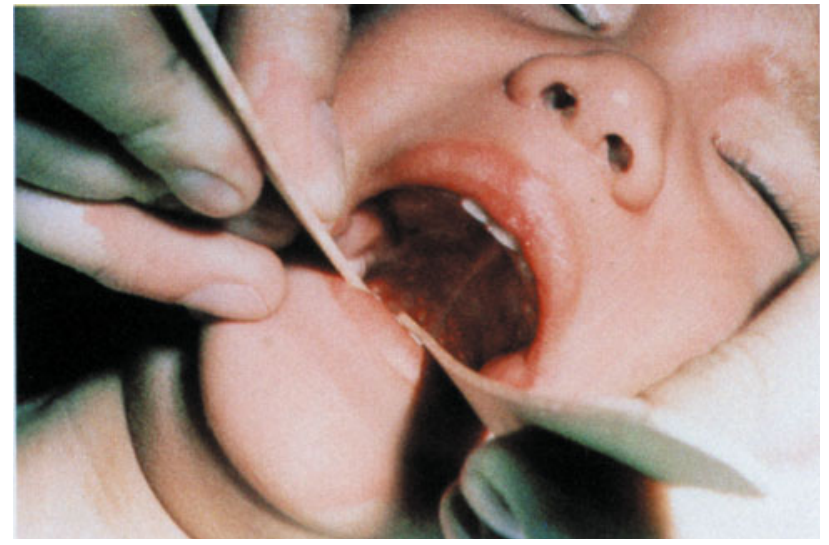

Figure 4-1. Herpangina lesions (white papules on a red base) on posterior palate (see p. 223).

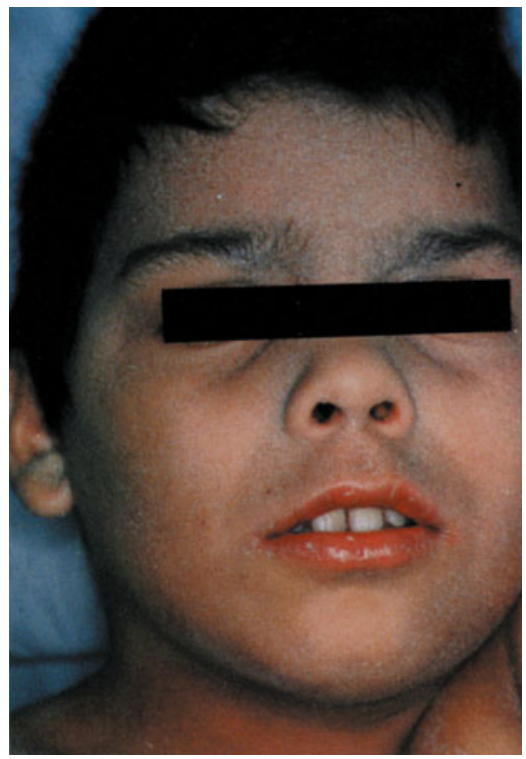

Figure 6-3. Scleral and cutaneous jaundice in patient with acute hepatitis (see p. 437).

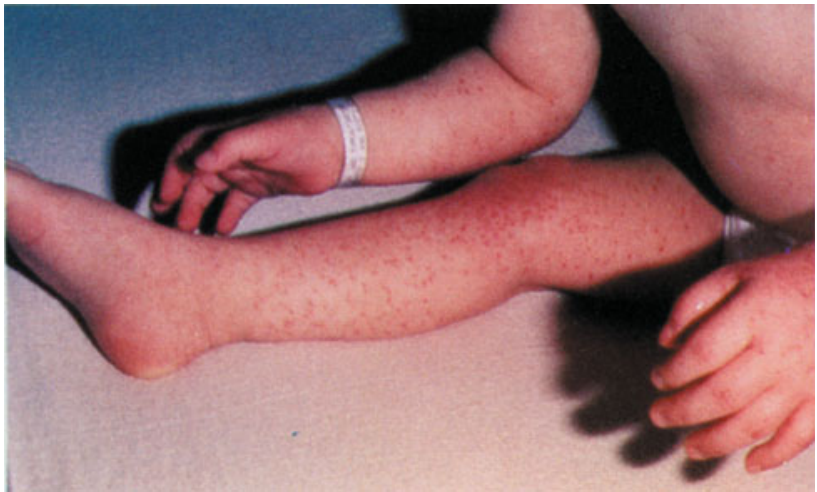

Figure 6-4. Papular acrodermatitits of Gianotti disease (see $\mathrm{p}$. 437). 


\section{Color Insert $\mathbf{x x X V}$}
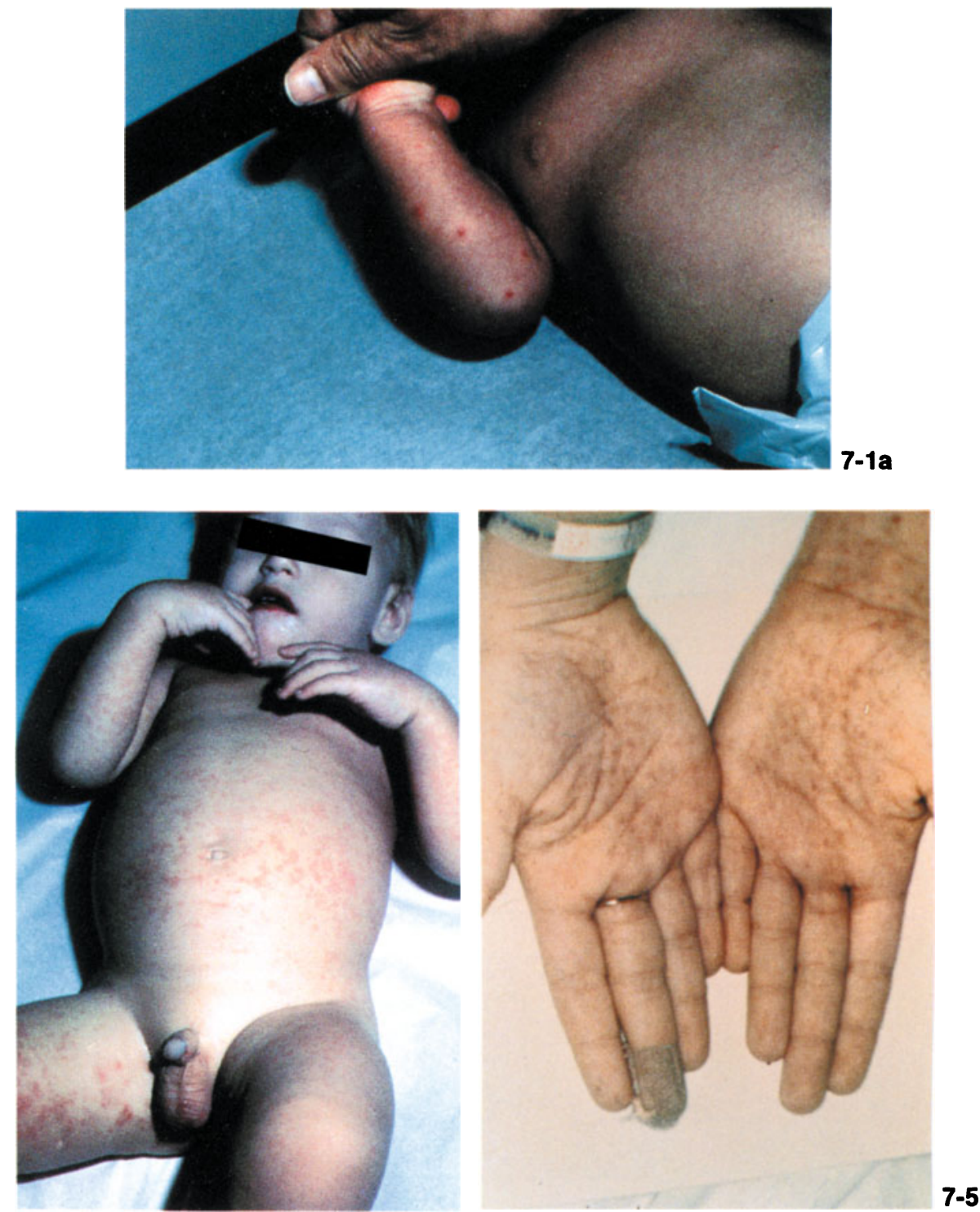

Figure 7-1. Cutaneous manifestations of ECHO virus 11 infection in two infants. (Courtesy of Dr. B. Brann.) (See p. 478).

Figure 7-5. Atypical measles rash on palms (see p. 485). 


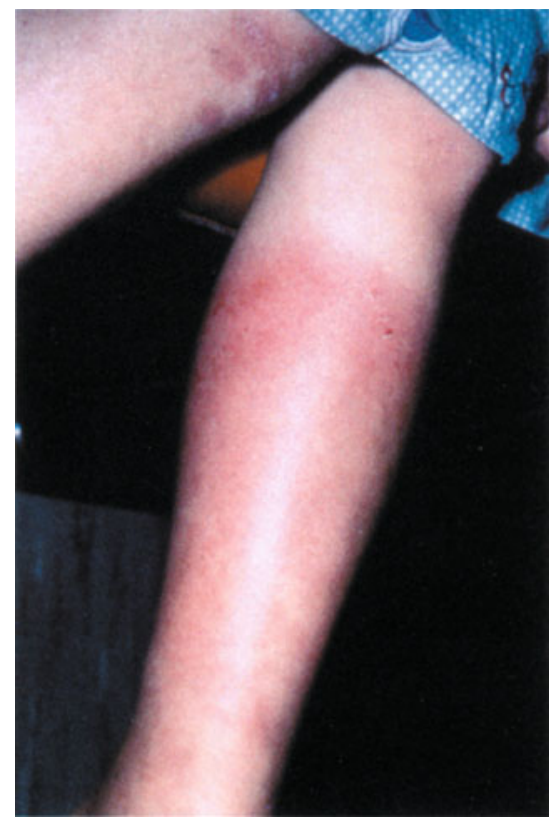

Figure 7-15. Streptococcal cellulitis (see p. 513).

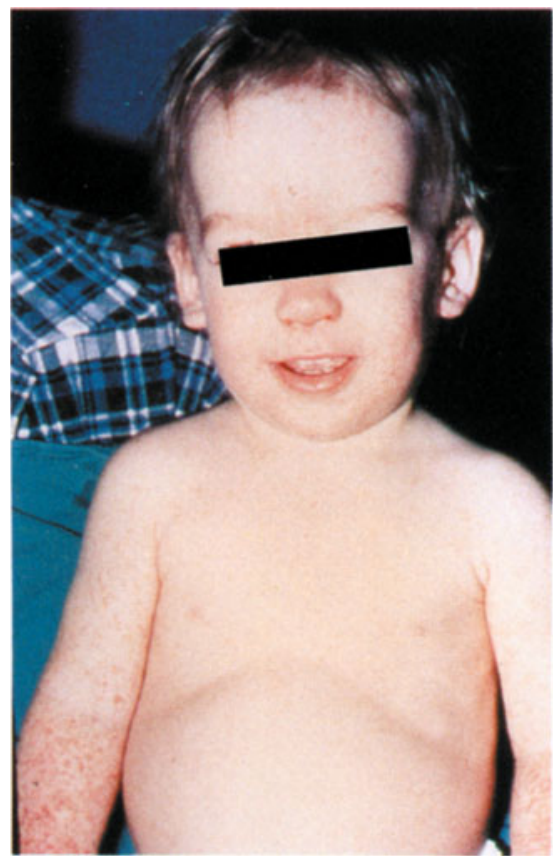

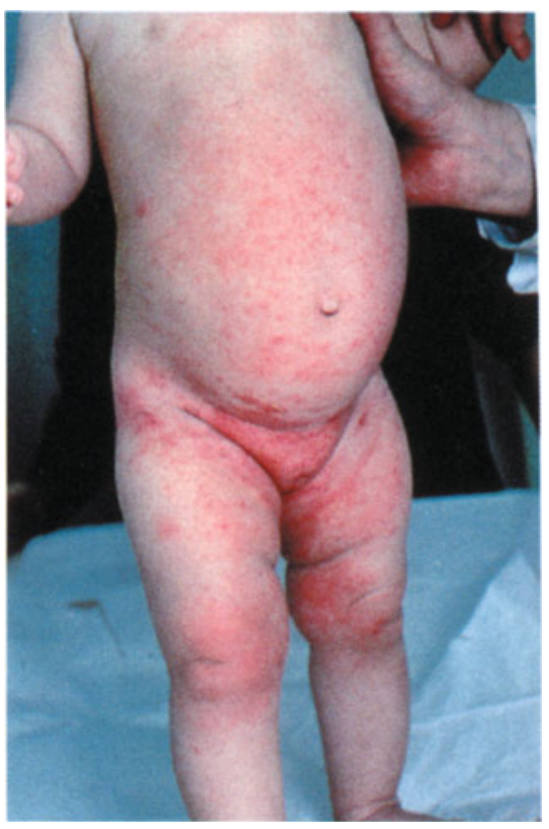

Figure 7-22. Dermatitis due to Epidermphyton floccosum. (Courtesy of Dr. B. Brann.) (See p. 537).

Figure 12-3. Skin eruption after the administration of ampicillin in a patient with infectious mononucleosis (see p. 737). 